(Supporting Information)

\title{
Instantaneous Inclusion of a Polynucleotide and Hydrophobic Guest Molecules into a Helical Core of Cationic $\beta$-1,3-Glucan Polysaccharide
}

\author{
Masato Ikeda,${ }^{\dagger}$ Teruaki Hasegawa,${ }^{\dagger}{ }^{\S}$ Munenori Numata, ${ }^{\dagger}$ Kouta Sugikawa,${ }^{\dagger}$ \\ Kazuo Sakurai, * Michiya Fujiki, " Seiji Shinkai ${ }^{* *}$ \\ ${ }^{\dagger}$ Department of Chemistry and Biochemistry, Graduate School of Engineering, Kyushu University, \\ Motooka 744, Nishi-ku, Fukuoka 819-0395, Japan, ${ }^{\ddagger}$ Department of Chemical Processes and \\ Environments, Faculty of Environmental Engineering, The University of Kitakyushu, Hibikino 1-1, \\ Wakamatsu-ku, Kitakyushu, Fukuoka 808-0315, Japan, ${ }^{9}$ Graduate School of Materials Science, Nara \\ Institute of Science and Technology, Takayama 8916-5, Ikoma, Nara 630-0101, Japan, and ${ }^{\S}$ Present \\ address: Department of Life Sciences, Faculty of Life Sciences, Toyo University, Izumino 1-1-1, \\ Itakuramachi, Oora-gun, Gunma 374-0193, Japan
}

Email: seijitcm@mbox.nc.kyushu-u.ac.jp

\section{Contents:}

1. Experimental details $\quad$ S2

2. Characterization of CUR-N ${ }^{+} \quad$ S5

3. UV-vis and fluorescence spectra of fluorescence probes in the presence of $\beta$-1,3-glucan polysaccharides

3-1. UV-vis and fluorescence spectra of ANS S8

3-2. UV-vis and fluorescence spectra of TNS $\quad$ S9

3-3. CD spectrum of TNS $\quad$ S9

$\begin{array}{lr}\text { 4. Effect of } \mathrm{NaCl} \text { on CUR-N } \\ \text {-poly(C) complex } & \mathrm{S} 10\end{array}$

$\begin{array}{ll}\text { 5. Complexation between chitosan and poly }(\mathrm{C}) & \mathrm{S} 11\end{array}$

$\begin{array}{ll}\text { 6. DLS analyses of CUR-N }{ }^{+} \text {-poly }(\mathrm{C}) \text { complex } & \mathrm{S} 12\end{array}$

$\begin{array}{ll}\text { 7. TEM image of CUR-N } \mathrm{N}^{+} \text {-PMDS composite } & \text { S13 }\end{array}$

8. AFM image of CUR-N ${ }^{+}-S W N T s$ composite $\quad$ S13

$\begin{array}{ll}\text { References } & \text { S14 }\end{array}$ 


\section{Experimental Details}

Materials. Curdlan (MW = 1,000,000) was obtained from Wako Chemicals. Polycytidylic acid (poly $(\mathrm{C})$ ) (potassium salt, lyophilized, $\mathrm{NB}=570$ ) was purchased from Amersham Pharmacia. Ribonuclease A (RNase A, E.C.3.1.27.5) was purchased from SIGMA. SWNTs produced by the Hipco (high-pressure decomposition of carbon monoxide) process were obtained from Carbon Nanotechnologies, Inc. RNase-free distilled sterile water and $1 \mathrm{M}$ TRIS-HCl ( $\mathrm{pH}$ 8.0) were obtained from Nippon Gene and spectroscopic grade DMSO were obtained from Kishida Chemicals and used for all measurements. All other starting materials and solvents were purchased from Tokyo Kasei Chemicals, Wako Chemicals, Kishida Chemicals, and Aldrich and used as received. Propargyltrimethylammonium chloride salt was synthesized according to the method reported previously. ${ }^{1}$

Instruments. ${ }^{1} \mathrm{H}$ and ${ }^{13} \mathrm{C}$ NMR spectra were obtained on a Brucker DRX600 or AC 250P spectrometer. 2,2-Dimethyl-2-silapentane-5-sulfonate sodium salt (DSS) was used as reference for $\mathrm{D}_{2} \mathrm{O}$ as solvent. The IR spectra were measured using a Perkin-Elmer Spectrum One FT-IR spectrometer. The absorption including NIR and circular dichroism (CD) spectra were measured in a $1-\mathrm{cm}$ quartz cell using a Jasco V-570 spectrometer and a Jasco J-710 spectropolarimeter, respectively. The fluorescence spectra were measured using a Perkin-Elmer LS-55 luminescence spectrometer. The atomic force microscopy (AFM) measurements were performed using a Nanoscope IIIa microscope (Veeco Instruments, Santa Barbara, CA) in air at ambient temperature with standard silicon cantilevers (RTESP, Veeco Instruments, Santabarbara, CA) in tapping mode. The nanoscope image processing software was used for the image analysis. TEM images were acquired using a JEOL TEM-2010 (accelerating voltage: $120 \mathrm{kV}$, beam current: $65 \mu \mathrm{A}$ ). Dynamic light scattering (DLS) was measured using a Malvern Zeta Sizer Nano ZS incorporating non-invasive back scatter optics $\left(\right.$ NIBS, $173^{\circ}$ ) with a laser source of He-Ne $633 \mathrm{~nm}$. Size exclusion chromatography (SEC) was performed with a Jasco PU-1580 Plus liquid chromatograph system equipped with a UV-visible detector (UV-1570 Plus), an RI detector (RI-2031 Plus) and a column oven (CO-2060 Plus). A SEC column (Shodex OHpak SB-806M HQ) was connected and $\mathrm{H}_{2} \mathrm{O}$ containing $100 \mathrm{mM}$ of $\mathrm{NaNO}_{3}$ was used as the eluent at a flow rate of $0.5 \mathrm{~mL} / \mathrm{min}$ at $40{ }^{\circ} \mathrm{C}$. Molecular modeling was performed on SGI WS with an insight II/Discover 3.0 program using CVFF force field. The starting main-chain conformation of CUR-N ${ }^{+}$was based on the crystal 
structure of triple-stranded helical structure of curdlan. ${ }^{2}$ The crystal structure of poly(C) were used as an initial structure of poly(C). ${ }^{3}$ Two strands of CUR-N $\mathrm{N}^{+}$and one strand of poly(C) were brought close and the length between the $\mathrm{H}$ atom of $\mathrm{OH}$ group at the $\mathrm{C} 2$ position of CUR- $\mathrm{N}^{+}$and the $\mathrm{N} 3$ atom of cytosine ring of poly(C) was fixed as $2.8 \AA$ based on an assumption of the presence of hydrogen bonding between them. ${ }^{4}$ The constructed model was optimized by the conjugate gradient method until the room-mean-square value became less than $0.1 \mathrm{kcal} \mathrm{mol}^{-1} \AA^{-1}$.

\section{Sample preparation for UV-vis and CD spectroscopic measurements of} CUR-N $\mathbf{N}^{+}$-poly(C) complex. Typical procedure is described. An aqueous solution of poly(C) $(1.0 \mathrm{mg} / \mathrm{mL}, 2.91 \mathrm{mM}$ (monomer unit as potassium salts), $100 \mu \mathrm{L})$ was diluted with Tris- $\mathrm{HCl}$ buffer $(1.0 \mathrm{mM}, \mathrm{pH} 8.0,1000 \mu \mathrm{L})$. To this solution was added Cur- $\mathrm{N}^{+}$in water $(5.0 \mathrm{mg} / \mathrm{mL}$, $15.6 \mathrm{mM}, 100 \mu \mathrm{L},\left(5.0\right.$ eq. Cur- $\mathrm{N}^{+} /$poly(C)). The resultant solution was incubated at $4{ }^{\circ} \mathrm{C}$ for at least 2 days and then subjected to the UV-vis and CD spectroscopic measurements.

\section{Sample preparation for AFM and TEM microscopic observations of CUR-N $\mathrm{N}^{+}-\operatorname{poly}(C)$} complex. Diluted solution (1/10 solution of the sample used for the UV-vis and CD spectroscopic measurements: CUR-N ${ }^{+}(8 \mu \mathrm{g} / \mathrm{mL})$, poly(C) $(10 \mu \mathrm{g} / \mathrm{mL})$, and CUR-N ${ }^{+}-\operatorname{poly}(\mathrm{C})$ (CUR-N ${ }^{+} 8,16$, and $40 \mu \mathrm{g} / \mathrm{mL}$ and poly(C) $10 \mu \mathrm{g} / \mathrm{mL}$ )) was casted on a freshly cleaved mica followed by Ar blowing dry. The substrate was dried under reduced pressure for at least 6 hours and subjected for AFM observation. The same solution was placed on a copper TEM grid upon an elastic carbon-support film $(20 \sim 25 \mathrm{~nm})$. The TEM grid was dried under reduced pressure for at least 6 hours prior to TEM observation.

Enzymatic hydrolysis of poly $(\mathbf{C})$. The increment of CMP concentration arising from the hydrolysis of poly(C) chain by RNase A was monitored by UV-vis spectroscopic measurements. ${ }^{5} \quad$ The CMP concentration was calculated from the absorbance at $260 \mathrm{~nm}$ using the values of exciton coefficient $(\varepsilon)$ : $6.9 \times 10^{3} \mathrm{~cm}^{-1} \mathrm{M}^{-1}$ for CMP, $5.1 \times 10^{3} \mathrm{~cm}^{-1} \mathrm{M}^{-1}$ for poly $(\mathrm{C})$, and $6.0 \times 10^{3} \mathrm{~cm}^{-1} \mathrm{M}^{-1}$ for CUR-N $\mathrm{N}^{+}$-poly $(\mathrm{C})$, respectively. The final condition was as follows: $[\operatorname{poly}(\mathrm{C})]=0.12 \mathrm{mM},\left[\right.$ CUR- $\left.\mathrm{N}^{+}\right]=0.60 \mathrm{mM},[$ Tris- $\mathrm{HCl}(\mathrm{pH} 8.0)]=1.0 \mathrm{mM}$, and $[$ RNase A $]=$ $2.0 \times 10^{-4} \mathrm{gL}^{-1}$. 
Preparation of PMDS/CUR-N ${ }^{+}$composites. PMDS $(0.5 \mathrm{mg})$ was weighted in a $2-\mathrm{mL}$ sample tube. To the tube was added $100 \mu \mathrm{L}$ of CUR-N ${ }^{+}$aqueous solution (12 mM (2.6 $\mathrm{mg} / \mathrm{mL})$ ) and sonicated for $50 \mathrm{~min}$ using a probe type sonicator $(50 \mathrm{~W}, 20 \mathrm{kHz}$ ) with the sample immersed in a water bath. Resultant dispersion was subjected to centrifugation at $3000 \mathrm{rpm}$ for $30 \mathrm{~min}$ to remove unwrapped PMDS as precipitate and the procedure was repeated two times. The supernatant was diluted by four-fold with distilled water and subjected to spectroscopic and microscopic experiments. The remained precipitate was dissolved in hexane and the solution was subjected to UV-vis spectroscopic measurements to estimate the amount of uncomplexed PMDS. The solution $(5 \mu \mathrm{L})$ of CUR-N ${ }^{+}$-PMDS was casted on a copper TEM grid upon an elastic carbon-support film $(20 \sim 25 \mathrm{~nm})$. The TEM grid was dried under reduced pressure for at least 6 hours prior to TEM observation.

Preparation of ag-SWNTs/CUR-N $\mathbf{N}^{+}$composites. Hipco SWNTs $(1.12 \mathrm{mg})$ was weighted in a $2-\mathrm{mL}$ sample tube. To the tube was added $1 \mathrm{~mL}$ of CUR-N ${ }^{+}$aqueous solution $(5 \mathrm{mg} / \mathrm{mL})$ and sonicated for $50 \mathrm{~min}$ using a probe type sonicator $(50 \mathrm{~W}, 20 \mathrm{kHz})$ with the sample immersed in a water bath. Resultant dispersion was subjected to centrifugation at $5000 \mathrm{rpm}$ for $30 \mathrm{~min}$ to remove unwrapped SWNTs as precipitate and the procedure was repeated two times. The supernatant was subsequently treated with a centrifugation at $15000 \mathrm{rpm}$ for $60 \mathrm{~min}$ and the supernatant that contains the excess uncomplexed Cur- $\mathrm{N}^{+}$was pipetted off and the precipitated ag-SWNTs/CUR-N ${ }^{+}$composite was dispersed into water again. The procedure was repeated three times. The solution was diluted until the absorbance at $500 \mathrm{~nm}$ as $0.646(2.26 \mu \mathrm{g} / \mathrm{mL}$ of SWNTs based on $\varepsilon_{500 \mathrm{~nm}}=2.86 \times 10^{4} \mathrm{~cm}^{2} / \mathrm{g}$ (see reference 6)) with $1-\mathrm{mm}$ cell. The solution was stable for at least one month and used further experiments. The solution was further purified by size-exclusion column chromatography (Sephadex G-100, water) to remove remained free CUR-N ${ }^{+}$and bundled ag-SWNTs/CUR-N ${ }^{+}$composites. The fractionated solution $\left(1.49 \mu \mathrm{g} / \mathrm{mL}\right.$ of SWNTs based on $\left.\mathrm{Abs}_{500 \mathrm{~nm}}=0.425\right)$ was placed on a holey carbon coated copper TEM grid and the TEM grid was dried under reduced pressure for at least 6 hours prior to TEM observation. The same solution was casted on a freshly cleaved mica and the substrate was dried under reduced pressure for at least 6 hours and subjected for AFM observation.

Synthesis of CUR-N ${ }^{+}$. To a solution of CUR-N ${ }_{3}^{7}(187 \mathrm{mg}, 1.0 \mathrm{mmol}$ (monomer unit)) in DMSO $\left(10 \mathrm{~mL}\right.$ ) (stirring for 2 hours at room temperature to dissolve CUR- $\mathrm{N}_{3}$ in DMSO 
completely) was added water $(1.0 \mathrm{~mL})$, propylamine $(1.0 \mathrm{~mL}), \mathrm{CuBr}_{2}(11.2 \mathrm{mg}, 5 \mathrm{~mol} \%)$, ascorbic acid (44.0 mg, $25 \mathrm{~mol} \%$ ), and 1-propynyl-trimethylammonoium chloride (668 mg, 5 eq. (monomer unit)). The solution was stirred at room temperature for 12 hours and dialyzed by distilled water with SpectraPor membrane (MWCO: 8000 , wet with $0.1 \%$ sodium azide) for 2 days and lyophilized using an LABCONCO freeze dryer 4.5 to afford CUR-N ${ }^{+}$as a white powder. Yield: $302 \mathrm{mg}(94 \%) .{ }^{1} \mathrm{H}$ NMR $\left(600 \mathrm{MHz}, 2.0 \mathrm{mg} / \mathrm{mL}, \mathrm{D}_{2} \mathrm{O}, 25{ }^{\circ} \mathrm{C}\right): \delta=8.45(\mathrm{~s}, 1 \mathrm{H}$, triazole- $\mathrm{H}$ ), $4.93\left(\mathrm{br}, 1 \mathrm{H}, \mathrm{H}^{1}\right), 4.72$ (br, $2 \mathrm{H}$ (overlapped with water), $\mathrm{NC}_{2}$ ), 3.86 (br, $2 \mathrm{H}, \mathrm{H}^{6}$ and $\mathrm{H}^{3}$ ), $3.66\left(\mathrm{br}, 2 \mathrm{H}, \mathrm{H}^{6}\right.$ and $\left.\mathrm{H}^{5}\right), 3.40\left(\mathrm{br}, 2 \mathrm{H}, \mathrm{H}^{2}\right.$ and $\left.\mathrm{H}^{4}\right), 3.18\left(\mathrm{br}, 9 \mathrm{H}, \mathrm{NC}_{3}\right) ;{ }^{13} \mathrm{C} \mathrm{NMR}(125$ $\left.\mathrm{MHz}, 5.0 \mathrm{mg} / \mathrm{mL}, \mathrm{D}_{2} \mathrm{O}, 25{ }^{\circ} \mathrm{C}\right): \delta=138.06,128.64,105.12,86.09,75.96,73.78,71.23,62.47$, 55.35, 51.78; FTIR (powder, $\mathrm{cm}^{-1}$ ): 3352, 2905, 1587, 1475, 1072, 897, 551; SEC (Shodex OHpak SB-806M HQ, $0.1 \mathrm{M} \mathrm{NaNO}_{3}$ aq, $40{ }^{\circ} \mathrm{C}$, pullulan standards) $M_{w}\left(M_{W} / M_{n}\right)=3.2 \times 10^{4}$ (1.6).

\section{Characterization of CUR-N $\mathrm{N}^{+}$.}

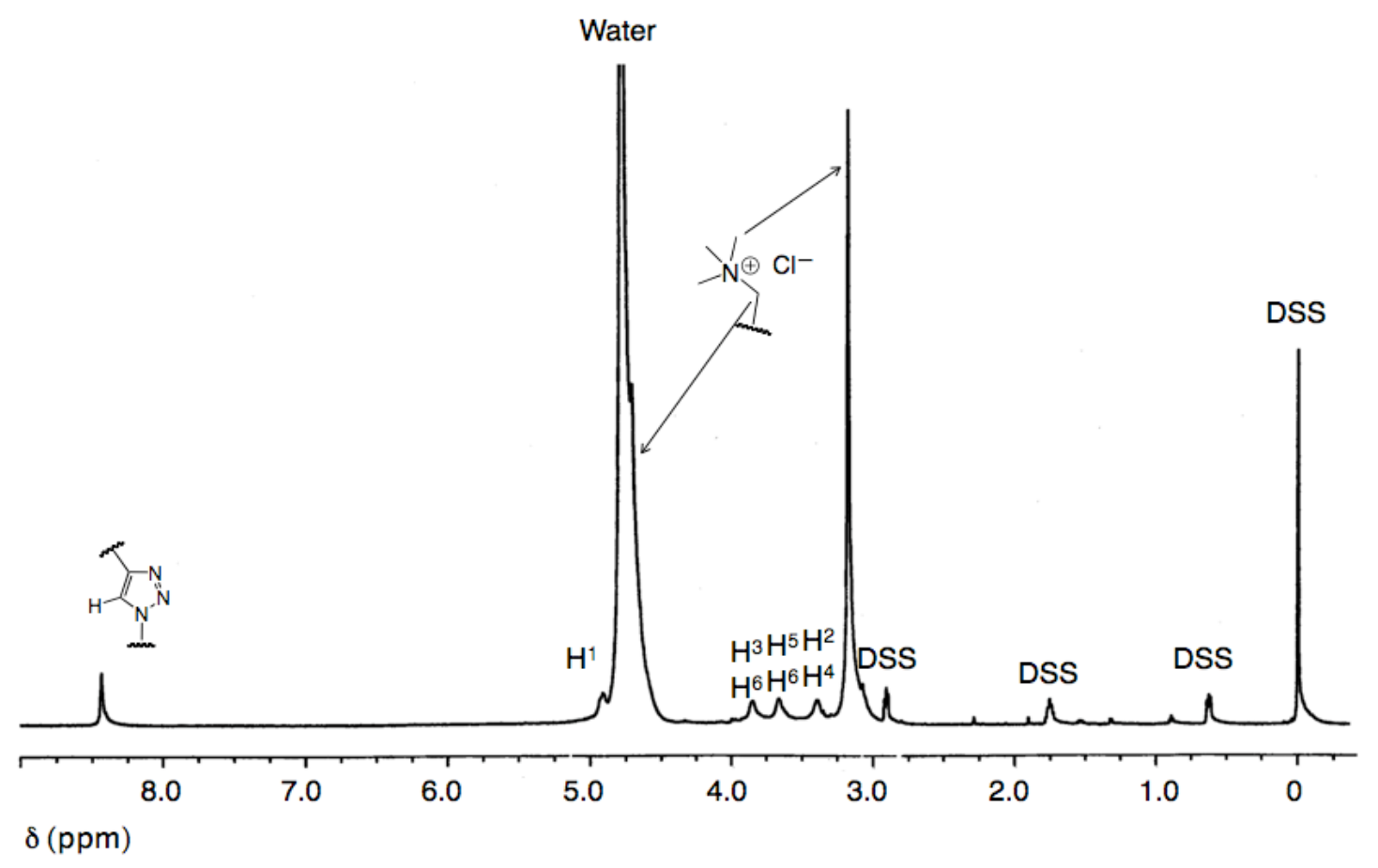

Figure S1. ${ }^{1} \mathrm{H}$ NMR (600 MHz) spectrum of CUR-N ${ }^{+}(2.0 \mathrm{mg} / \mathrm{mL})$ in $\mathrm{D}_{2} \mathrm{O}$ (DSS standard) at $25^{\circ} \mathrm{C}$. 


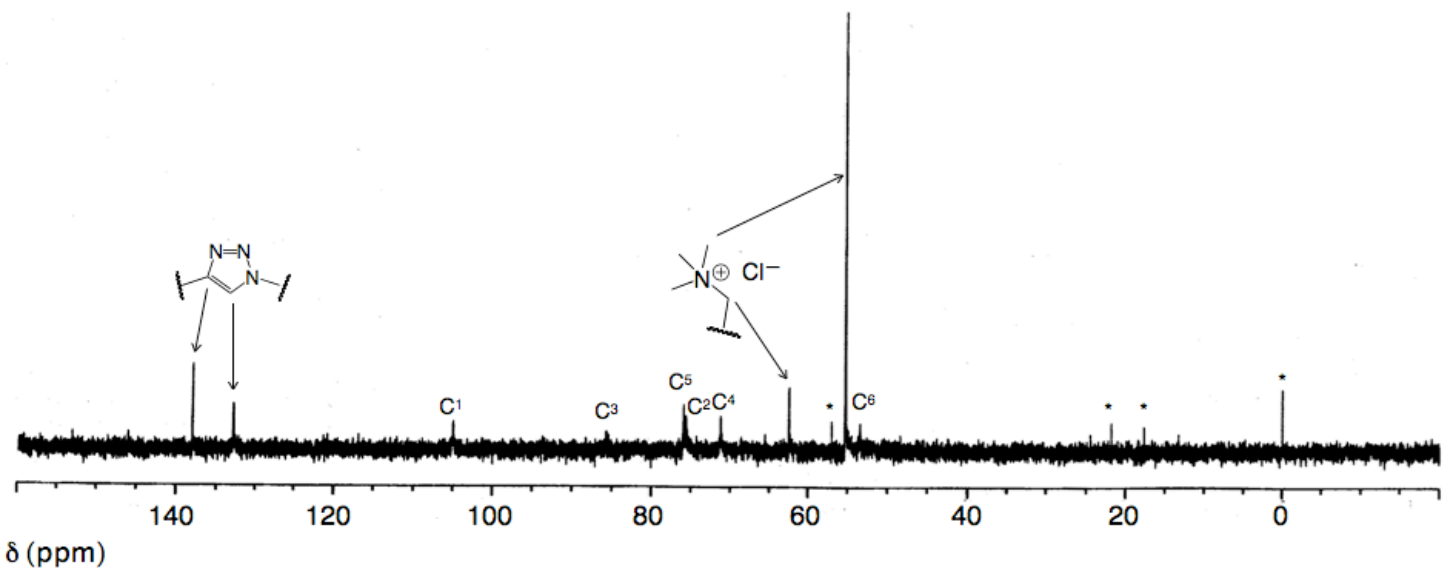

Figure S2. ${ }^{13} \mathrm{C}$ NMR spectrum $(150 \mathrm{MHz})$ of CUR- $\mathrm{N}^{+}(5.0 \mathrm{mg} / \mathrm{mL})$ in $\mathrm{D}_{2} \mathrm{O}$ (the mark "**" indicates the peaks of DSS) at $25^{\circ} \mathrm{C}$. 


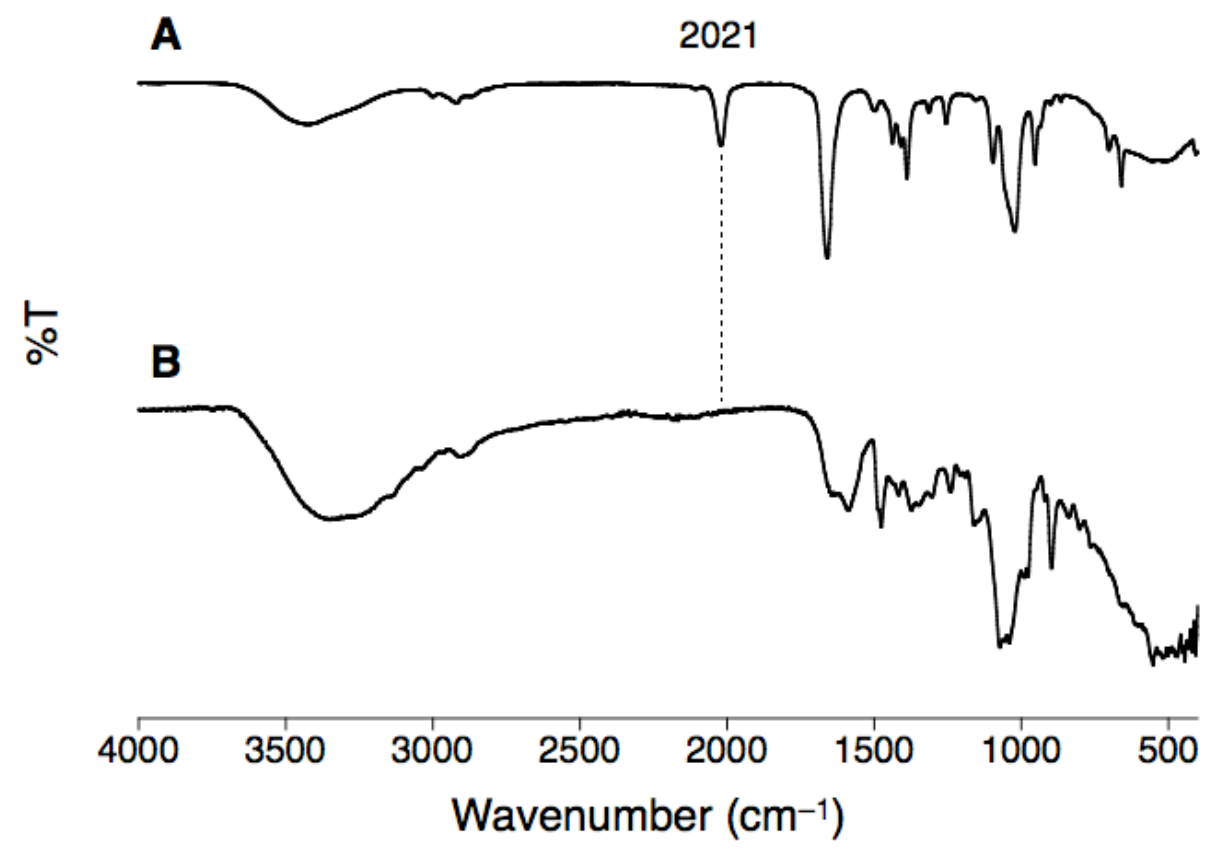

Figure S3. IR spectra (ATR method) of (A) CUR-N $\mathrm{N}_{3}$ and (B) CUR-N ${ }^{+}$.

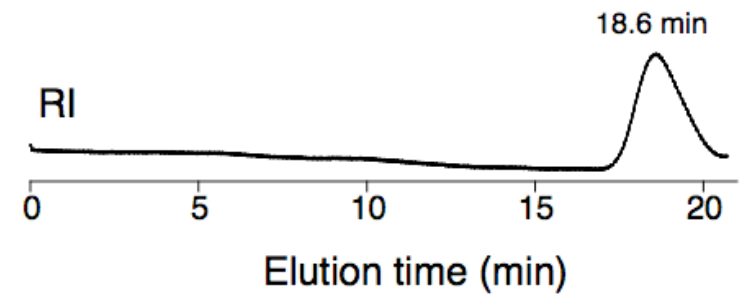

Figure S4. SEC chromatogram of CUR-N $\mathrm{N}^{+}$. 


\section{3-1. UV-vis and fluorescence spectra of ANS.}
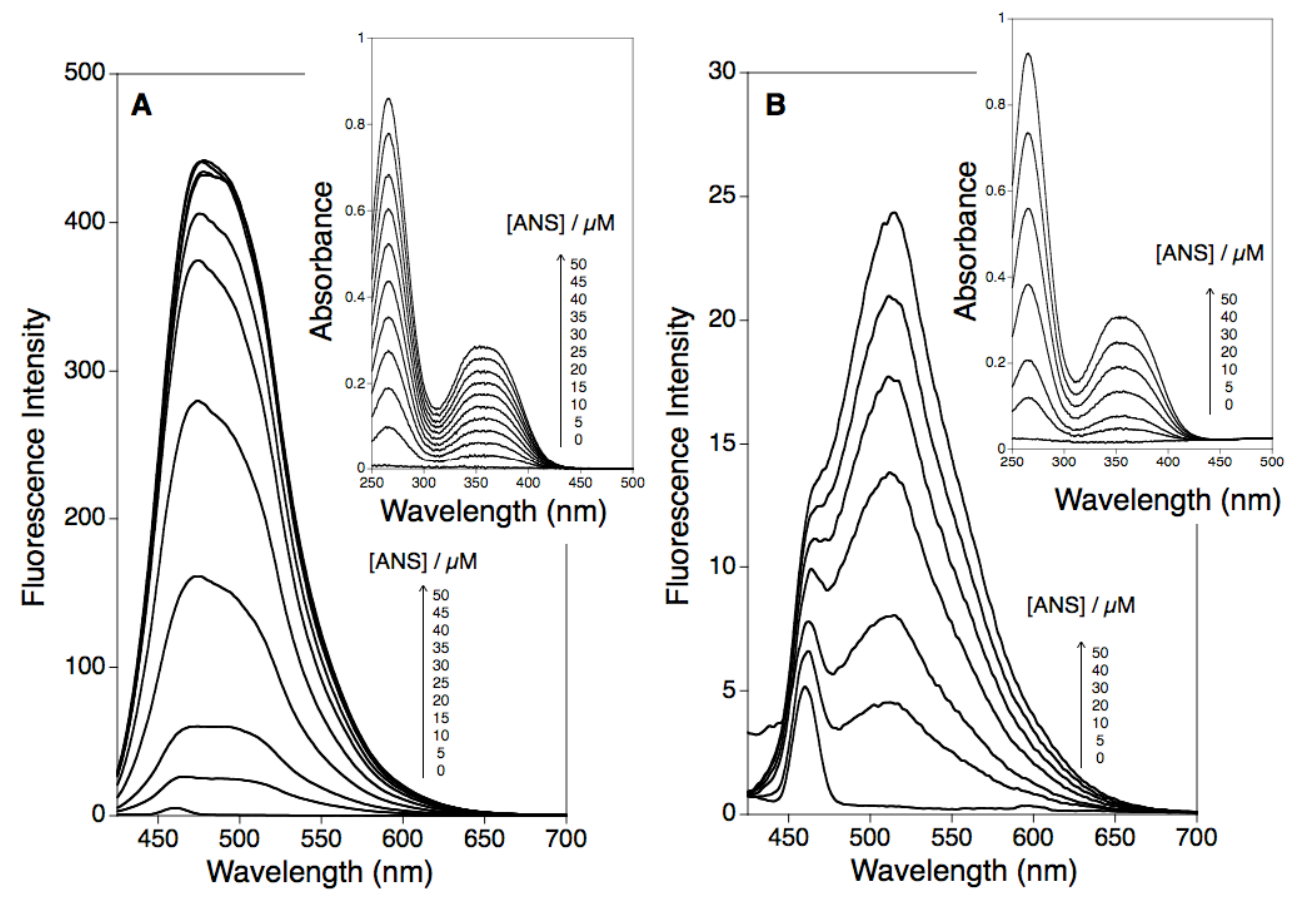

Figure S5. Concentration dependence of UV-vis (Inset) and fluorescence spectra of ANS (ANS concentration is shown in Figure) $\left(\lambda_{\mathrm{ex}}=370 \mathrm{~nm}\right)$ in the presence of (A) CUR-N $\mathrm{N}^{+}(10 \mu \mathrm{M})$ or (B) SPG (10 $\mu \mathrm{M})$ in water at ambient temperature. 


\section{3-2. UV-vis and fluorescence spectra of TNS}
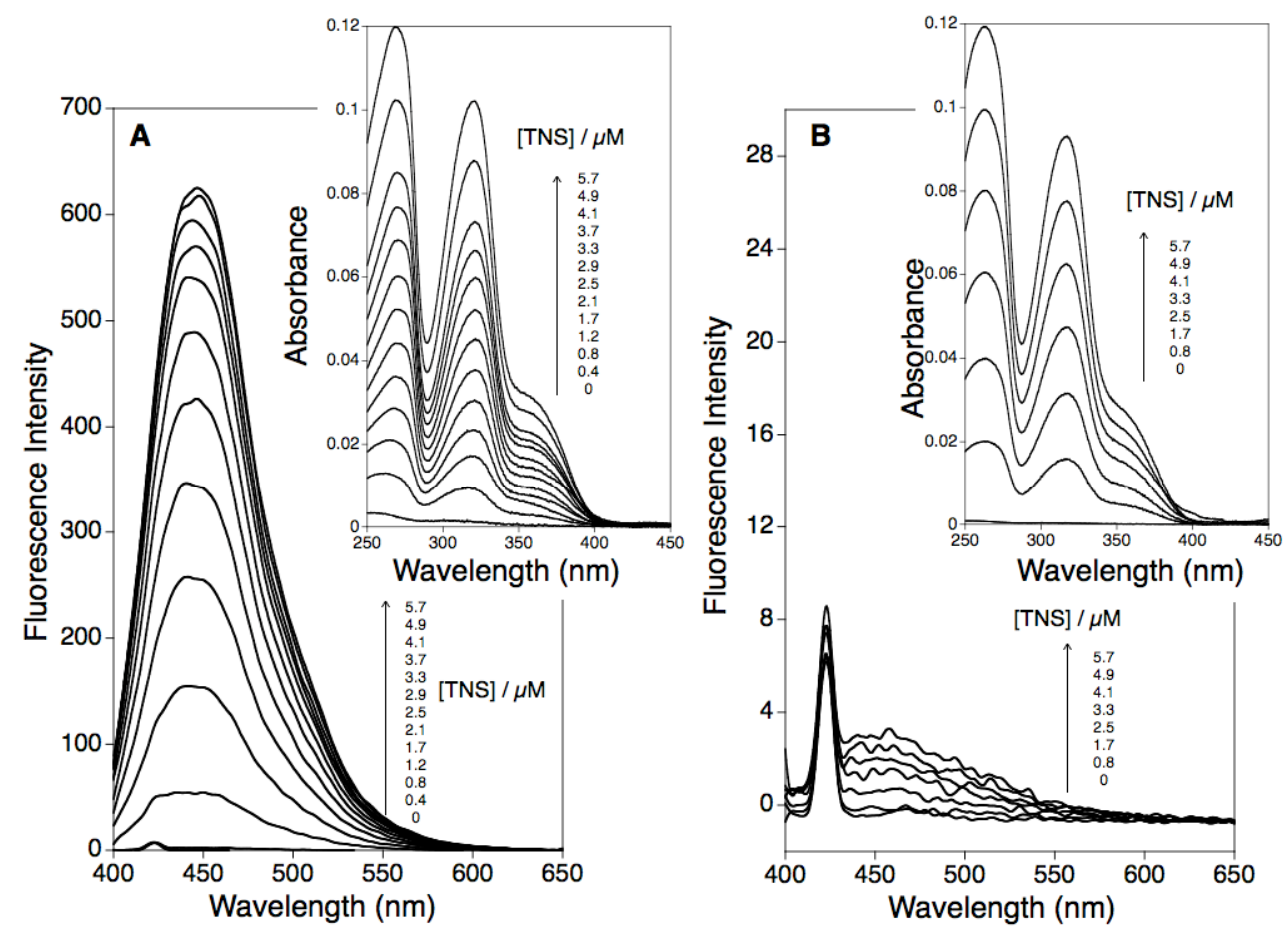

Figure S6. Concentration dependence of UV-vis (Inset) and fluorescence spectra of TNS (TNS concentration is shown in Figure) $\left(\lambda_{\mathrm{ex}}=370 \mathrm{~nm}\right)$ in the presence of (A) CUR-N $\mathrm{N}^{+}(10 \mu \mathrm{M})$ or (B) SPG (10 $\mu \mathrm{M})$ in water at ambient temperature.

\section{3-3. CD spectrum of TNS.}

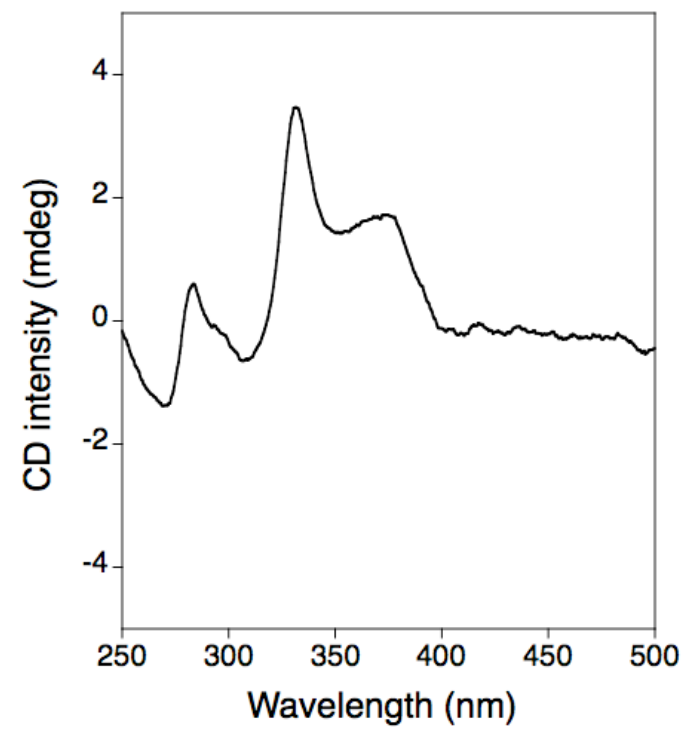

Figure S7. CD spectrum of TNS $(5.7 \mu \mathrm{M})$ in the presence of CUR-N ${ }^{+}(10 \mu \mathrm{M})$ in water at ambient temperature using $1-\mathrm{cm}$ cell. 


\section{Effect of $\mathrm{NaCl}$ on $\mathrm{CUR}-\mathrm{N}^{+}-\operatorname{poly}(\mathrm{C})$ complex.}

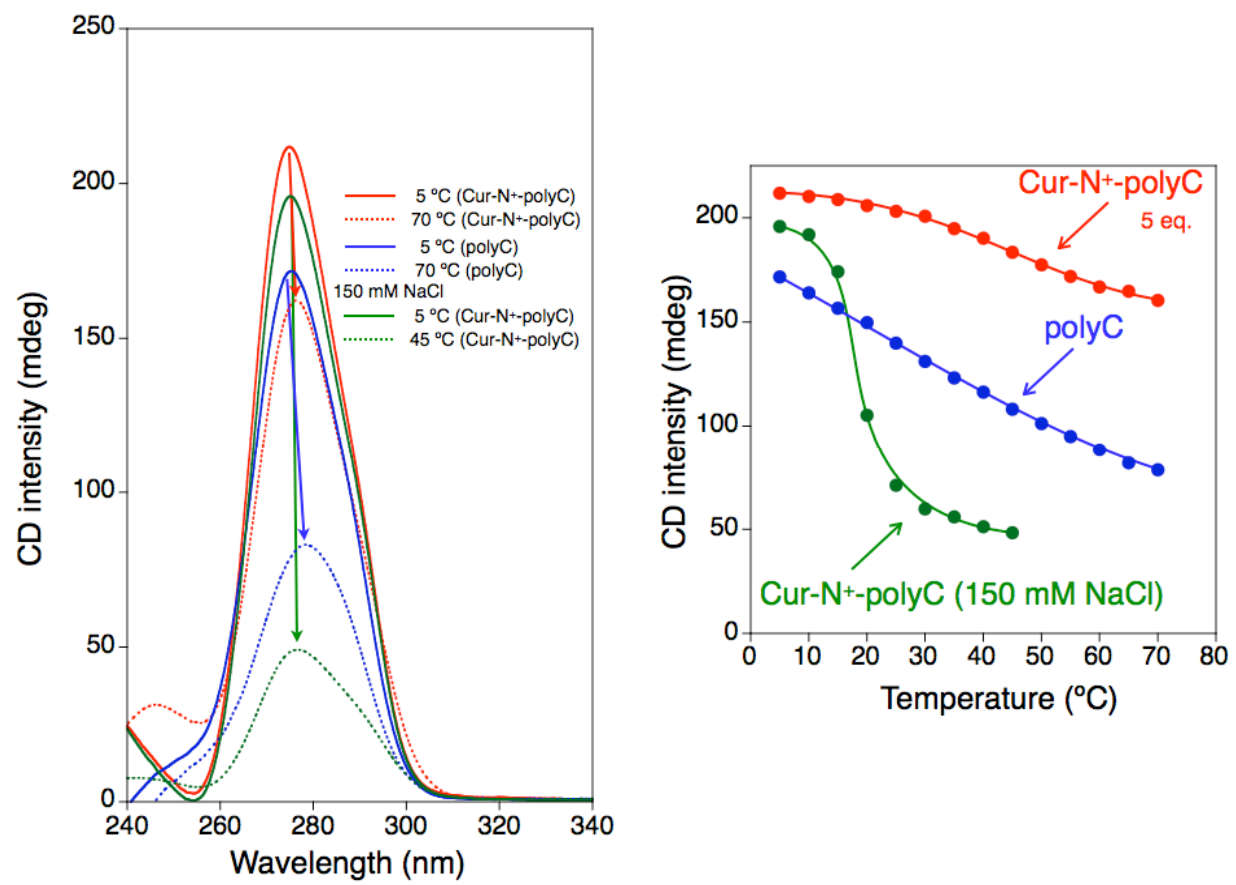

Figure S8. Comparison of the CD spectra of poly(C) (0.24 mM (monomer unit)), CUR-N ${ }^{+}-$poly(C) $(1.3$ $\mathrm{mM}$ (monomer unit), $0.24 \mathrm{mM}$ (monomer unit)) in the presence or absence of $\mathrm{NaCl}(150 \mathrm{mM})$ in $1.0 \mathrm{mM}$ Tris- $\mathrm{HCl}$ buffer $(\mathrm{pH} 8.0)$ at $5{ }^{\circ} \mathrm{C}$ and $70{ }^{\circ} \mathrm{C}$ or $45^{\circ} \mathrm{C}$ with a 1 -cm cell. 


\section{Complexation between chitosan and poly $(C)$.}
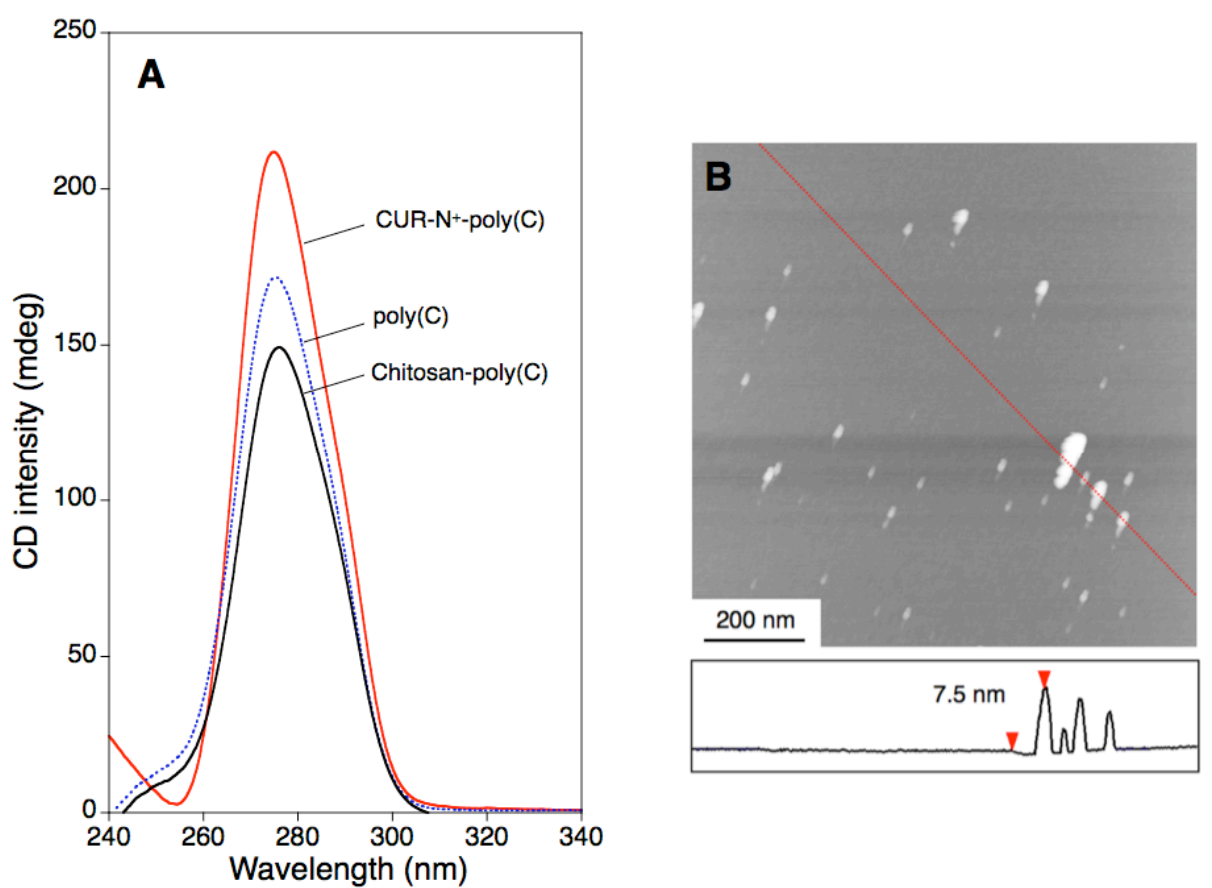

Figure S9. (A) Comparison of the CD spectra of poly(C) (0.24 mM (monomer unit)), CUR-N ${ }^{+}-$poly(C) (1.3 mM (monomer unit), $0.24 \mathrm{mM}$ (monomer unit)), and chitosan-poly(C) (1.3 mM (monomer unit), $0.24 \mathrm{mM}$ (monomer unit)) in $1.0 \mathrm{mM}$ Tris- $\mathrm{HCl}$ buffer $(\mathrm{pH} 8.0)$ at $5{ }^{\circ} \mathrm{C}$ with a $1-\mathrm{cm}$ cell and (B) AFM height image of chitosan-poly $(\mathrm{C})$ on mica and the cross section profile along the dotted line in the image. 
6. DLS analyses of CUR-N ${ }^{+}-\operatorname{poly}(\mathrm{C})$ complex.
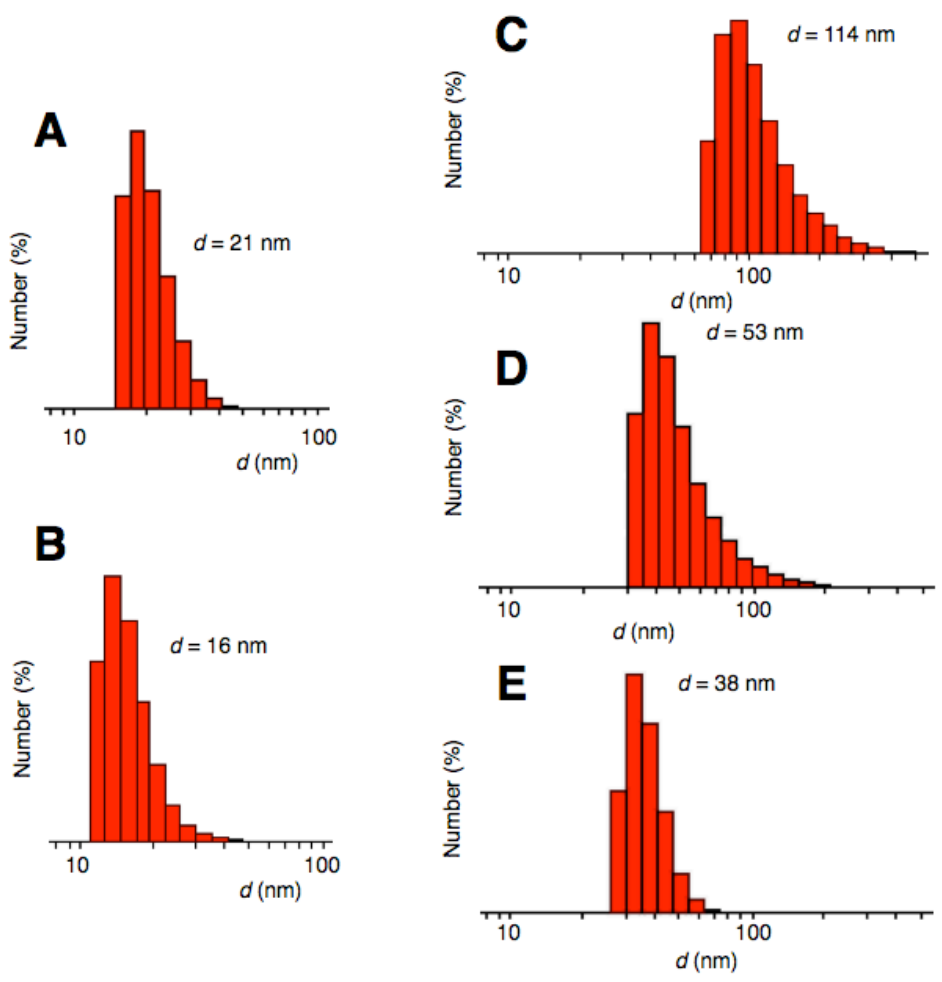

Figure S10. Histogram analyses of DLS for (A) CUR-N ${ }^{+}(1.3 \mathrm{mM})$, (B) poly(C) $(0.24 \mathrm{mM}),(\mathrm{C})$ CUR-N ${ }^{+}$-poly(C) (0.24 mM (1.0 eq), $\left.0.24 \mathrm{mM}\right)$, (D) CUR-N ${ }^{+}$-poly(C) $(0.48 \mathrm{mM}(2.0 \mathrm{eq}), 0.24 \mathrm{mM})$, and (E) CUR-N ${ }^{+}$-poly(C) $(1.3 \mathrm{mM}(5.0 \mathrm{eq}), 0.24 \mathrm{mM})$ in $1.0 \mathrm{mM}$ Tris- $\mathrm{HCl}$ buffer $(\mathrm{pH} 8.0)$ at $25^{\circ} \mathrm{C}$. 
7. TEM image of CUR-N $\mathrm{N}^{+}$-PMDS composite.

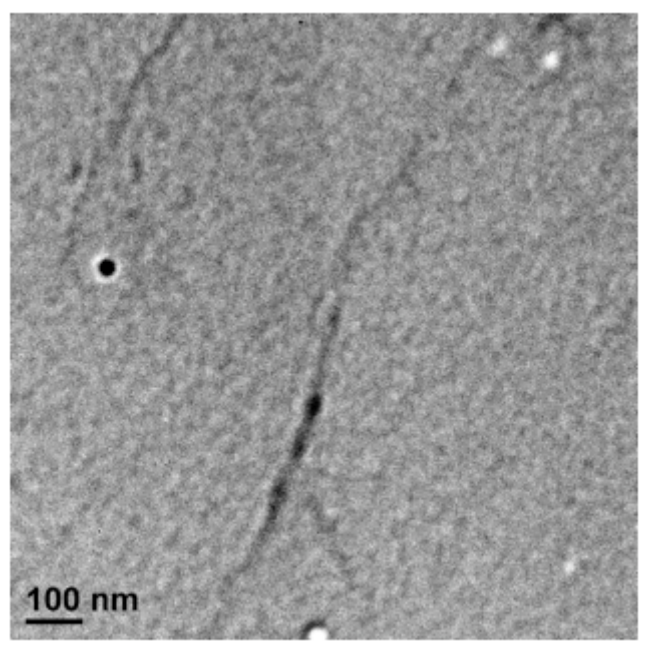

Figure S11. Unstained TEM image of CUR-N ${ }^{+}$PMDS composite.

8. AFM image of CUR-N ${ }^{+}-S W N T s$ composite.

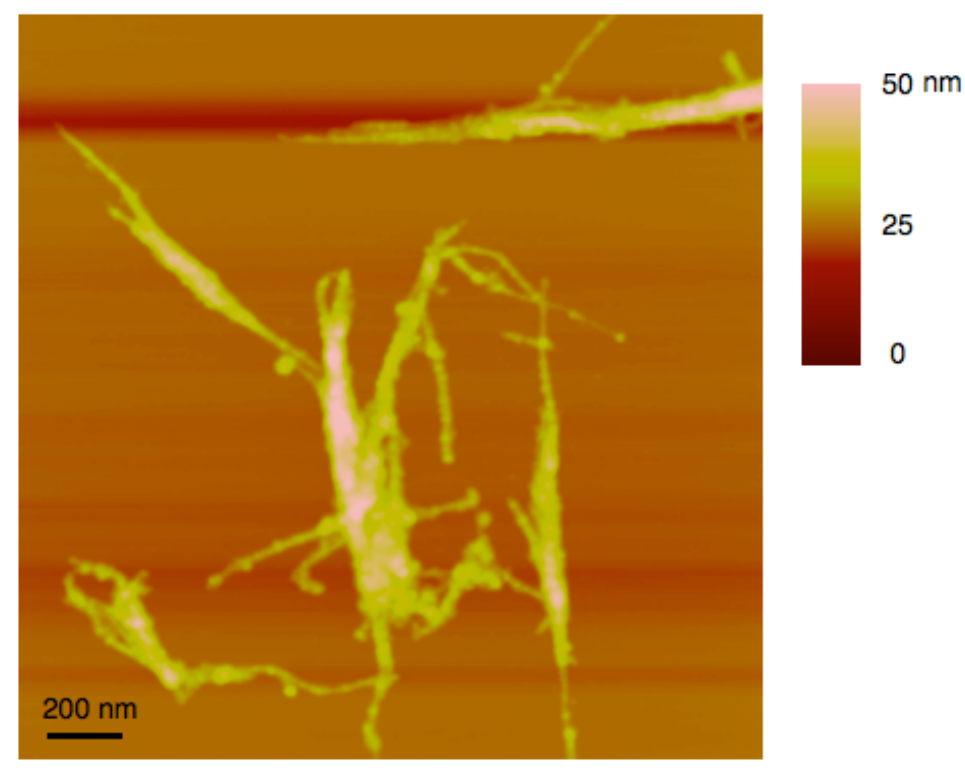

Figure S12. AFM height image of CUR-N ${ }^{+}-S W N T s$ composite before chromatographic purification. 


\section{References}

(1) Nguyen, H.-K.; Fournier, O.; Asseline, U.; Dupret, D.; Thuong, N. T. Nucleic Acids Res. 1999, 27, 1492-1498.

(2) Sathyanarayana, B. K.; Rao, V. S. R. Biopolymers 1971, 10, 1605-1615.

(3) Arnott, S.; Chandrasekaran, R.; Leslie, A. G. W. J. Mol. Biol. 1976, 106, 735-736.

(4) Miyoshi, K.; Uezu, K.; Sakurai, K.; Shinkai, S. Biomacromolecules 2005, 6, 1540-1546.

(5) Mizu, M.; Koumoto, K.; Kimura, T.; Sakurai, K. Shinkai, S. Biomaterials 2004, 25, 3109-3116.

(6) Bahr, J. L.; Mickelson, E. T.; Bronikowski, M. J.; Smalley, R. E.; Tour, J. M. Chem. Commun. 2001, 193-194.

(7) (a) Hasegawa, T.; Umeda, M.; Numata, M.; Li, C.; Bae, A.-H.; Fujisawa, T.; Haraguchi, S.; Sakurai, K.; Shinkai, S. Chem. Lett. 2006, 35, 82-83. (b) Hasegawa, T.; Umeda, M.; Numata, M.; Li, C.; Bae, A.-H.; Fujisawa, T.; Haraguchi, S.; Sakurai, K.; Shinkai, S. Carbohydr. Res. 2006, 341, 35-40. 